\title{
BMJ Open Prevalence of risk factors for coronary artery disease in an urban Indian population
}

\author{
T Sekhri, ${ }^{1}$ R S Kanwar, ${ }^{1}$ R Wilfred, ${ }^{1}$ P Chugh, ${ }^{1}$ M Chhillar, ${ }^{1}$ R Aggarwal, ${ }^{1}$ \\ Y K Sharma, ${ }^{2}$ J Sethi, ${ }^{1} \mathrm{~J}$ Sundriyal, ${ }^{1} \mathrm{~K}$ Bhadra, ${ }^{1}$ S Singh, ${ }^{1}$ N Rautela, ${ }^{1}$ Tek Chand, ${ }^{1}$ \\ M Singh, ${ }^{1}$ S K Singh ${ }^{1}$
}

To cite: Sekhri T, Kanwar RS, Wilfred $\mathrm{R}$, et al. Prevalence of risk factors for coronary artery disease in an urban Indian population. BMJ Open 2014;4:e005346. doi:10.1136/bmjopen-2014005346

- Prepublication history for this paper is available online. To view these files please visit the journal online (http://dx.doi.org/10.1136/ bmjopen-2014-005346).

Received 26 March 2014 Accepted 20 August 2014

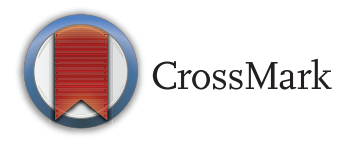

${ }^{1}$ Division of Health, Endocrinology and Thyroid Research, Institute of Nuclear Medicine and Allied Sciences (INMAS), Defence Research and Development

Organisation (DRD0), Delhi, India

${ }^{2}$ Department of Biostatistics, Defence Institute of Physiology and Allied Sciences (DIPAS), Defence Research and Development Organisation (DRDO), Delhi, India

Correspondence to Dr Tarun Sekhri; tarunsekhri@yahoo.com

\section{ABSTRACT}

Objective: The objective of this study was to assess the prevalence of risk factors for coronary artery disease (CAD) in government employees across India. Methods: The study population consisted of government employees in different parts of India ( $n=10642$ men and $n=1966$ women; age 2060 years\}) and comprised various ethnic groups living in different environmental conditions. Recruitment was carried out in 20 cities across 14 states, and in one union territory. All selected individuals were subjected to a detailed questionnaire, medical examinations and anthropometric measurements. Blood samples were collected for blood glucose and serum lipid profile estimation, and resting ECG was recorded. Results were analysed using appropriate statistical tools.

Results: The study revealed that $4.6 \%$ of the study population had a family history of premature CAD. The overall prevalence of diabetes was $16 \%$ (5.6\% diagnosed during the study and the remaining $10.4 \%$ already on medication). Hypertension was present in $21 \%$ of subjects. The prevalence of dyslipidemia was significantly high, with $45.6 \%$ of study subjects having a high total cholesterol/high density lipoprotein ratio. Overall, $78.6 \%$ subjects had two or more risk factors for CAD.

Conclusions: The present study demonstrates a high prevalence of CAD risk factors in the Indian urban population. Therefore, there is an immediate need to initiate measures to raise awareness of these risk factors so that individuals at high risk for future CAD can be managed.

\section{INTRODUCTION}

Coronary artery disease (CAD) is one of the most common causes of mortality and morbidity in both developed and developing countries. It is a leading cause of death in India, and its contribution to mortality is rising: the number of deaths due to CAD in 1985 is expected to have doubled by $2015 .^{1}$ According to reports from the National Commission on Macroeconomics and Health, 62 million people in India will have CAD by

\section{Strengths and limitations of this study}

- Our study is the first of its type to investigate people of diverse ethnicities and age groups living in various cities in different parts of India.

- Qualified doctors took histories and clinically examined all subjects, while all biochemical investigations were conducted using similar kits and evaluation techniques.

- A limitation of this study was that only 14500 of approximately 26000 employees gave informed consent, and only data from 12608 of these participants were analysed.

- The limited resources allocated to phase I meant we could only study conventional coronary risk factors.

2015, with 23 million of these below 40 years of age. ${ }^{2}$ The prevalence of classic cardiovascular risk factors such as hypertension, dyslipidemia, obesity and diabetes, varies widely between different countries, and shows some important secular trends. The conventional risk factors for CAD can be divided into nonmodifiable and modifiable risk factors. The former include age, sex and family history, while the latter include diabetes mellitus (DM), smoking, dyslipidemia, hypertension and obesity. There is increasing incidence indicating that Asian Indians are at increased risk of CAD, which cannot be attributed to the common risk factors. Recently, a number of newer cardiovascular risk factors have been identified, which are of great interest as more than $60 \%$ of CAD in native Indians remains unexplained by conventional risk factors. Comparative studies on newer risk factors show that Indians have higher C-reactive protein, plasminogen activator inhibitor (PAI-1) and homocysteine levels. ${ }^{3}$

The incidence of CAD is likely to increase further because of rapid urbanisation and its accompanying lifestyle changes, including changes in diet, physical inactivity, drug and 
alcohol intake, as well as an increase in the prevalence of DM. $^{45}$ The prevalence of risk factors in a population determines the future burden on healthcare services and the loss of an individual's productive years. Risk factors constitute a health risk for the individual and impose an overall burden on the economy. There are no large scale studies of adequate sample size to evaluate the prevalence of risk factors, risk factor patterns and electrocardiographic changes in Indian populations. The present study was thus planned to evaluate the future risk of CAD in a national organisation. As the organisation has offices across the entire country (figure 1), the study population included subjects from various ethnic groups, living in various environments and consuming different diets. To the best of our knowledge the present study is the first of its kind conducted across India.

\section{MATERIALS AND METHODS}

\section{Patient population and study design}

All subjects were civilian government employees working in various parts of the country. Subjects of both sexes and aged from 20 to 60 years were enrolled after written informed consent was obtained. Recruitment was carried in 20 cities across 14 states and in one union territory in India, namely: Delhi (Delhi), Karnataka (Bangalore, Mysore), Andhra Pradesh (Hyderabad, Vishakahapatnam), Maharashtra (Pune, Ambernath, Ahmednagar), Uttar Pradesh (Agra, Kanpur), Rajasthan (Jodhpur), Himachal Pradesh (Manali), Chandigarh, Uttrakhand (Dehradun, Mussourrie), Orissa (Chandipur), Assam (Tejpur), Jammu and Kashmir (Leh), Madhya Pradesh (Gwalior), Tamil Nadu (Chennai) and Kerala (Kochi). Recruitment began in 2009 and phase 1 evaluation was completed in 2012. The sample size calculation was not performed as it was an open study where voluntary participation of all employees was encouraged.

\section{Inclusion and exclusion criteria}

To be included, a subject had to be: (a) a civilian government employee working in any area of the country; (b) apparently healthy; (c) aged 20-60 years; and (d) either male or female. A subject was excluded if they were known to have CAD.

\section{Assessment process}

Participants were asked to visit the health centre of their employment organisation at 8:00 am after an overnight fast. They were asked to continue their medication, if any, as usual. A detailed questionnaire was administered by medical personnel before clinical measurements and blood collection. The questionnaire recorded information on demographic data, socio-economic details and marital status. Information on several lifestyle factors was also recorded, including tobacco, alcohol and caffeine consumption, physical activity, family history, disease history, medication use, and family history of premature $\mathrm{CAD}$ in first degree relatives (age $<55$ years in men and
$<65$ years in women). In women, further data regarding reproductive and obstetric history, oral contraception and hormonal replacement therapy were collected.

Anthropometric and clinical examination including blood pressure (BP) measurement was carried out for each subject. Body weight and height were measured with participants standing without shoes in light clothes. Bodyweight was measured in kilograms to the nearest $0.1 \mathrm{~kg}$ using a digital scale, which was calibrated regularly. Height was measured to the nearest $5 \mathrm{~mm}$ using a height gauge. Body mass index (BMI), defined as weight

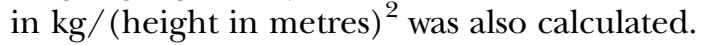

BP and heart rate were measured on the left arm, with an appropriately sized cuff, after at least $10 \mathrm{~min}$ of rest in the seated position, using an automated BP instrument. The average of the last two measurements was used for analysis. The subjects diagnosed as having high $\mathrm{BP}$ for the first time were recalled the next day for BP monitoring before they were diagnosed as hypertensive. Resting ECG was also obtained as part of the evaluation.

Blood samples were collected in the fasting state and $2 \mathrm{~h}$ after $75 \mathrm{~g}$ of oral glucose administration. Biochemical evaluation of blood samples included complete blood count, fasting plasma glucose (FPG), post-prandial plasma glucose (PPPG), lipid profile, and liver and kidney function tests. The clinical chemistry tests were performed on fresh blood samples using automatic analysers on the same day. Subjects whose FPG was $\geq 126 \mathrm{mg} / \mathrm{dL}$ and/or PPPG $\geq 200 \mathrm{mg} / \mathrm{dL}$ were diagnosed as new cases of DM. Other subjects with a past history of DM and/or taking medication for DM were also considered to have diabetes.

When lipid profiles were being calculated, a total cholesterol/high density lipoprotein (HDL) cholesterol value of $\geq 4.5$ was considered abnormal. Known cases of dyslipidemia and/or those on medication for dyslipidemia were considered to have the dyslipidemia risk factor. Table 1 summarises the definitions for the different risk factors in the study.

The strength of the study was that each participant had personal contact with at least one of the project team doctors. Each questionnaire was scrutinised by a doctor. This added value to the data as in most epidemiological studies paramedics usually collect the data.

\section{Statistical analysis}

The final data were recorded on a predesigned performa and managed in Microsoft Access. Data analysis was performed using SPSS V.20.0. The values of various parameters are presented as means $\pm \mathrm{SD}$, in absolute numbers and as percentages. Data for men and women were compared using the $\mathrm{t}$ test. Correlation statistics between various risk factors were also computed. The minimum significance level was set at 0.05 .

\section{Ethics approval}

The study was approved by the Institutional Ethics Committee of the Institute of Nuclear Medicine and Allied Sciences (INMAS), Delhi. 


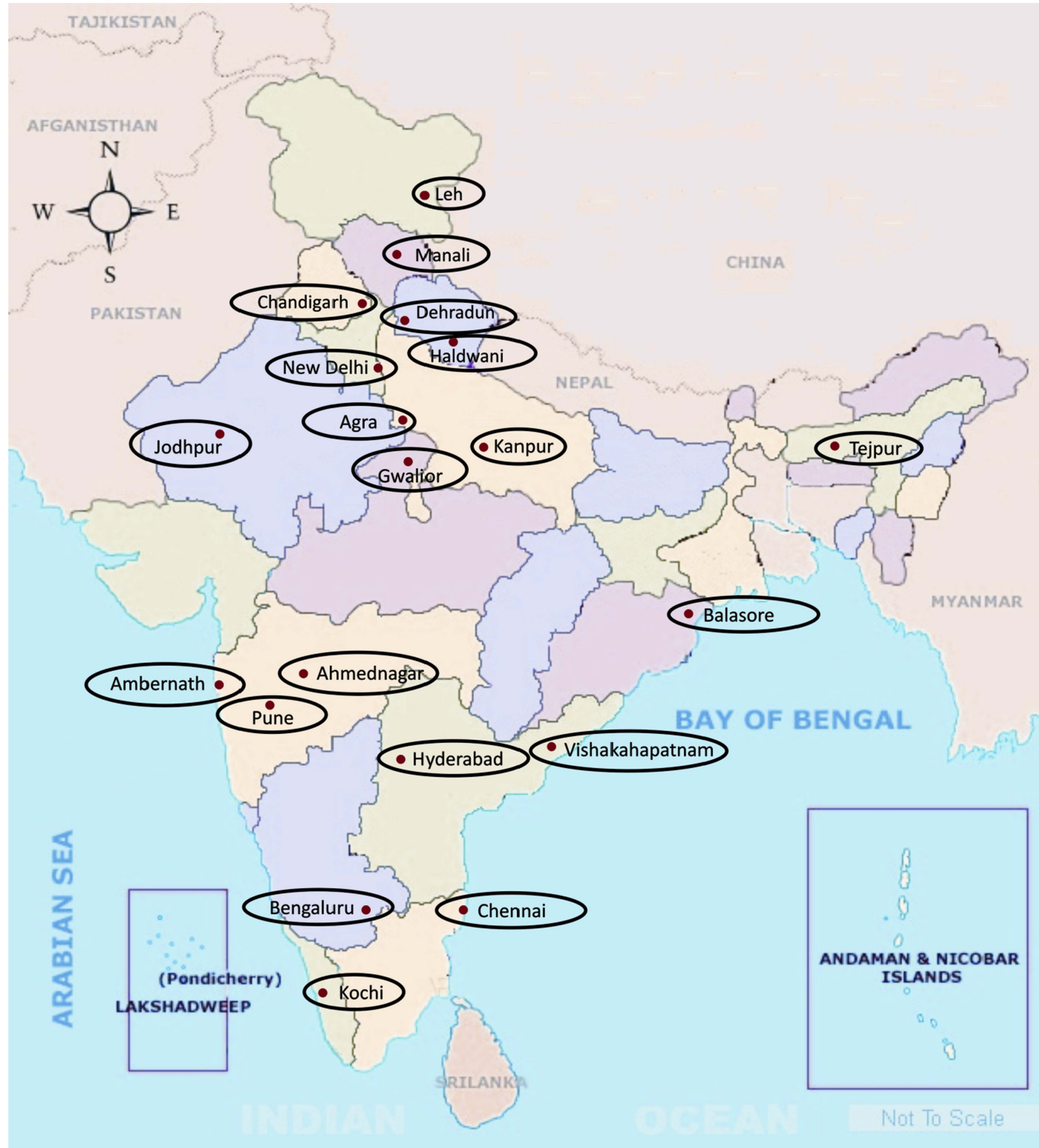

Figure 1 Locations in India where the study was carried out.

\section{RESULTS}

A total of 14500 subjects were evaluated in the study. After informed consent was obtained, exclusion criteria were applied, and clinical and biochemical assessment was carried out, complete data for 12608 subjects (10 642 men and 1966 women) were available for final analysis. The mean age of men was $44.34 \pm 10.63$ years, while their median age was 47.00 years. The mean age of women was $42.47 \pm 10.34$ years, while their median age was 44.00 years. Baseline characteristics are shown in table 2.

The different parameters considered for calculating the risk factors and their results are given in table 3 .

A family history of premature CAD was present in $4.6 \%$ of the study population: $4.4 \%$ of men and $6 \%$ of women had a first degree relative with a history of CAD 
Table 1 Definitions for the different risk factors in the study

\begin{tabular}{|c|c|}
\hline Risk factor & Definition \\
\hline Hypertension & $\begin{array}{l}\text { Systolic } \mathrm{BP} \geq 140 \mathrm{~mm} \mathrm{Hg} \text { and/or diastolic } \mathrm{BP} \geq 90 \mathrm{~mm} \mathrm{Hg} \text { during the visit and/or } \\
\text { presence of anti-hypertensive drug treatment; considered known if the subject was } \\
\text { aware of this condition }\end{array}$ \\
\hline Diabetes mellitus & $\begin{array}{l}\mathrm{FPG} \geq 126 \mathrm{mg} / \mathrm{dL} \text { and/or PPPG } \geq 200 \mathrm{mg} / \mathrm{dL} \text { at the time of investigation and/or } \\
\text { presence of anti-diabetic drug treatment; considered known if the subject was aware } \\
\text { of this condition }\end{array}$ \\
\hline Obesity & $\mathrm{BMl} \geq 30 \mathrm{~kg} / \mathrm{m}^{2}$ \\
\hline Overweight & $\mathrm{BMI} \geq 25 \mathrm{~kg} / \mathrm{m}^{2}$ \\
\hline Hypercholesterolaemia & Total blood cholesterol $\geq 200 \mathrm{mg} / \mathrm{dL}$ \\
\hline Decreased HDL cholesterol & $\leq 40 \mathrm{mg} / \mathrm{dL}$ \\
\hline $\begin{array}{l}\text { Adverse total cholesterol/HDL ratio } \\
\text { (dyslipidemia) }\end{array}$ & $\geq 4.5$ \\
\hline Age & $>45$ years in men and $>55$ years in women \\
\hline Sex & Male sex \\
\hline Family history of CAD & Premature $C A D$ in first degree relatives ( $<55$ years in men and $<65$ years in women) \\
\hline Risk factors for CAD & $\begin{array}{l}\text { Age, sex, family history, diabetes mellitus, smoking, dyslipidemia, hypertension and } \\
\text { obesity }\end{array}$ \\
\hline
\end{tabular}

$(\mathrm{p}<0.05)$. The prevalence of smoking was significantly higher in men $(13.8 \%)$ than in women $(0.1 \%)$ $(\mathrm{p}<0.001)$.

Of the 12608 study subjects, 6002 (47.6\%) had a BMI $\geq 25 \mathrm{~kg} / \mathrm{m}^{2}: 4910(46.1 \%)$ men and $1092(55.5 \%)$ women were overweight or obese $(\mathrm{p}<0.001)$. On further analysis it was observed that $39.46 \%$ of men and $38.6 \%$ of women were overweight (BMI $25-30 \mathrm{~kg} / \mathrm{m}^{2}$ ) $(\mathrm{p}<0.001)$. The mean BMI of the overweight men and women was $26.93 \pm 1.31$ and $27.35 \pm 1.44$, respectively. Obesity (BMI $\geq 30 \mathrm{~kg} / \mathrm{m}^{2}$ ) was present in $6.6 \%$ of men with a mean BMI of $32.78 \pm 4$ and in $16.7 \%$ of women with a mean BMI of $33.41 \pm 3.74(\mathrm{p}<0.05)$.

The overall prevalence of diabetes was $16 \%$ in the study population, with no significant difference between men $(16.6 \%)$ and women $(12.7 \%)$. These $16 \%$ comprised $5.6 \%$ who were diagnosed during the study and
$10.4 \%$ who had known DM and were already on medication.

Hypertension was identified in 2383 (22.4\%) of the 10642 men and in $264(13.4 \%)$ of the 1966 women $(\mathrm{p}<0.001)$. The overall prevalence of hypertension was $21 \%$ among study subjects. Of these subjects, only $4.76 \%$ were aware of they had the condition and were on medication, with a further $16.22 \%$ identified during the study.

The prevalence of dyslipidemia in the study population was significantly high, with $45.6 \%$ of study subjects having a high total cholesterol/HDL cholesterol ratio: $48.27 \%$ of men and $31.4 \%$ women were found to have dyslipidemia $(\mathrm{p}<0.001)$. The prevalence of hypercholesterolaemia in the study population was $31.3 \%$, with no significant difference between men $(32 \%)$ and women $(27.6 \%)$. When a cut-off value of $40 \mathrm{mg} / \mathrm{dL}$ was used,

Table 2 Baseline characteristics of the study population $(n=12608)$

\begin{tabular}{lccc}
\hline Parameters & $\begin{array}{l}\text { Men } \\
(\mathbf{n = 1 0 ~ 6 4 2 )}\end{array}$ & $\begin{array}{l}\text { Women } \\
(\mathbf{n = 1 9 6 6 )}\end{array}$ & $\mathbf{p}$ Value \\
\hline Age, years & $44.34 \pm 10.63$ & $42.47 \pm 10.34$ & 0.000 \\
Height, cm & $166.92 \pm 6.89$ & $154.74 \pm 6.34$ & 0.000 \\
Weight, kg & $69.36 \pm 10.69$ & $62.24 \pm 11.30$ & 0.001 \\
BMl & $24.89 \pm 3.58$ & $26.02 \pm 4.69$ & 0.001 \\
Systolic BP, mm Hg & $127.35 \pm 16.12$ & $120.05 \pm 15.25$ & 0.000 \\
Diastolic BP, mm Hg & $81.08 \pm 10.04$ & $77.05 \pm 9.60$ & 0.000 \\
FPG, mg/dL & $95.91 \pm 31.08$ & $93.48 \pm 32.10$ & 0.01 \\
PPPG, mg/dL & $135.44 \pm 56.31$ & $131.86 \pm 54.47$ & 0.01 \\
Total cholesterol, mg/dL & $186.11 \pm 40.56$ & $181.69 \pm 36.62$ & 0.001 \\
HDL, mg/dL & $42.46 \pm 11.55$ & $46.54 \pm 11.36$ & 0.001 \\
\hline
\end{tabular}

Values are mean \pm SD.

BMI, body mass index; BP, blood pressure; FPG, fasting plasma glucose; HDL, high density lipoprotein; PPPG, post-prandial plasma glucose. 
Table 3 Percentage (\%) of risk factors in the study population $(n=12608)$

\begin{tabular}{|c|c|c|c|c|}
\hline Parameters & $\begin{array}{l}\text { Total } \\
(n=12608)\end{array}$ & $\begin{array}{l}\text { Men } \\
(n=10642)\end{array}$ & $\begin{array}{l}\text { Women } \\
(n=1966)\end{array}$ & p Value \\
\hline Family history of CAD & $580(4.6 \%)$ & $460(4.4 \%)$ & $120(6 \%)$ & $<0.05$ \\
\hline Smoking & $1471(11.6 \%)$ & $1469(13.8 \%)$ & $2(0.1 \%)$ & $<0.001$ \\
\hline $\mathrm{BMI}>25 \mathrm{~kg} / \mathrm{m}^{2}$ & $6002(47.6 \%)$ & $4910(46.1 \%)$ & $1092(55.5 \%)$ & \\
\hline Mean $\pm S D$ & & $27.8 \pm 3.59$ & $29.17 \pm 3.66$ & $<0.001$ \\
\hline BMI 25-30 kg/m² & $4959(39.3 \%)$ & $4200(39.46 \%)$ & $759(38.6 \%)$ & \\
\hline Mean $\pm S D$ & & $26.93 \pm 1.31$ & $27.35 \pm 1.44$ & $<0.001$ \\
\hline $\mathrm{BMI} \geq 30 \mathrm{~kg} / \mathrm{m}^{2}$ & 1029 (8.2\%) & $700(6.6 \%)$ & $329(16.7 \%)$ & \\
\hline Mean $\pm S D$ & & $32.78 \pm 4.00$ & $33.41 \pm 3.74$ & $<0.05$ \\
\hline Diabetes mellitus & $2016(16 \%)$ & $1766(16.6 \%)$ & $250(12.7 \%)$ & NS \\
\hline Hypertension & $2647(21 \%)$ & $2383(22.4 \%)$ & $264(13.4 \%)$ & $<0.001$ \\
\hline Dyslipidemia & $5755(45.6 \%)$ & $5137(48.27 \%)$ & $618(31.4 \%)$ & $<0.001$ \\
\hline
\end{tabular}

Values are $\mathrm{n}(\%)$ unless otherwise indicated.

$\mathrm{BMI}$, body mass index; CAD, coronary artery disease.

$37.7 \%$ of men were found to have low HDL and similarly, when a cut-off value of $<50 \mathrm{mg} / \mathrm{dL}$ was used, $76 \%$ of women were found to have low HDL.

The study population was divided into four groups according to age. Subjects aged $20-30$ years $(n=1885)$, $30-40$ years $(n=2724), 40-50$ years $(n=3604)$ and 50 60 years $(\mathrm{n}=4395)$ were categorised as group I, group II, group III and group IV, respectively.

The mean level of total cholesterol in these age groups was: group I, $174.2 \mathrm{mg} / \mathrm{dL}$; group II, $182.5 \mathrm{mg} / \mathrm{dL}$; group III, $188.2 \mathrm{mg} / \mathrm{dL}$; and group IV, $189.7 \mathrm{mg} / \mathrm{dL}$. Levels were significantly higher in group II as compared with group I $(p<0.05)$. A significant difference was found when we compared group III with group II $(p<0.05)$. However, there was no significant difference when groups III and IV were compared. The mean HDL cholesterol levels in these age groups were: group I, $43.79 \mathrm{mg} / \mathrm{dL}$; group II, $42.53 \mathrm{mg} / \mathrm{dL}$; group III, $42.80 \mathrm{mg} / \mathrm{dL}$; and group IV, $43.37 \mathrm{mg} / \mathrm{dL}$. No significant difference was seen in the levels of HDL cholesterol among these age groups.

A total of $9909(78.6 \%)$ subjects had two or more risk factors for CAD: $9251(86.9 \%)$ men had two or more risk factors compared with $658(33.46 \%)$ women. The most prevalent risk factor in men was dyslipidemia (present in $48.27 \%$ of men), followed by a BMI $>25$ (present in $46.1 \%$ of men). In women, a BMI $>25$ was the most prevalent factor (present in $55.5 \%$ of women), followed by dyslipidemia in $31.45 \%$.

HDL correlated negatively with FPG, PPPG and BMI. BMI had a positive correlation with systolic and diastolic BP, FPG and PPPG, and total cholesterol. Total cholesterol had a positive correlation with systolic and diastolic BP, FPG and PPPG, and BMI (table 4).

\section{DISCUSSION}

This study investigated the prevalence of risk factors for $\mathrm{CAD}$ in a national organisation employing people in different regions of India. Participants were of both sexes and aged 20-60 years. It was found that approximately half of the study population had dyslipidemia (45.6\%) and approximately half had a BMI $>25 \mathrm{~kg} / \mathrm{m}^{2}(47.6 \%)$. About one fifth of the study population was hypertensive $(21 \%)$ and one sixth had DM $(16 \%)$. Two or more CAD risk factors were identified in $78.6 \%$ of participants, which indicates that there is a large population who will develop CAD in the near future.

The present results can be compared with the findings in 739 subjects (451 men and 288 women) of the Jaipur Heart Watch-5 study by Gupta et al. ${ }^{6}$ That study found that $46.2 \%$ of men and $50.7 \%$ of women were

Table 4 Correlations among risk factors by Pearson correlation (two-tailed) $(n=12608)$

\begin{tabular}{|c|c|c|c|c|c|c|c|}
\hline Parameters & Systolic BP & Diastolic BP & FPG & PPPG & $\begin{array}{l}\text { Serum } \\
\text { total cholesterol }\end{array}$ & Serum HDL & BMI \\
\hline Systolic BP & 1 & $0.715^{\star}$ & $0.149^{\star}$ & $0.136^{\star}$ & $0.086^{\star}$ & -0.011 & $0.190^{\star}$ \\
\hline Diastolic BP & $0.715^{*}$ & 1 & $0.119^{\star}$ & $0.107^{\star}$ & $0.114^{*}$ & -0.011 & $0.216^{\star}$ \\
\hline FPG & $0.149^{*}$ & $0.119^{*}$ & 1 & $0.821^{*}$ & $0.095^{\star}$ & $-0.054^{*}$ & $0.099^{*}$ \\
\hline PPPG & $0.136^{\star}$ & $0.107^{\star}$ & $0.821^{\star}$ & 1 & $0.092^{\star}$ & $-0.042^{*}$ & $0.117^{\star}$ \\
\hline Serum total cholesterol & $0.086^{*}$ & $0.114^{*}$ & $0.095^{\star}$ & $0.092^{*}$ & 1 & 0.000 & $0.063^{\star}$ \\
\hline Serum HDL cholesterol & -0.011 & -0.011 & $-0.054^{\star}$ & $-0.042^{*}$ & 0.000 & 1 & $-0.068^{*}$ \\
\hline BMI & $0.190^{*}$ & $0.216^{\star}$ & $0.099^{\star}$ & $0.117^{\star}$ & $0.063^{\star}$ & $-0.068^{*}$ & 1 \\
\hline
\end{tabular}


overweight or obese. The prevalence of hypertension was $39.5 \%$ in men and $24.6 \%$ in women, diabetes was present in $15.5 \%$ of men and in $10.85 \%$ of women, and $33 \%$ of men and $32.7 \%$ of women had high cholesterol levels.

Similar results were found by a study by Prabhakaran et $a l^{7}$ among men working in an industry in northern India. A high serum total cholesterol/HDL ratio was found in $62 \%$ of the population, overweight in $47 \%$, hypertension in $30 \%$ and diabetes in $15 \%$. Prabhakaran et al also showed that $47 \%$ of their subjects had at least two CAD risk factors, compared with $78.6 \%$ with two or more CAD risk factors in the present study.

Another study in 2008 by Mohan and Deepa showed the following prevalences of major risk factors for cardiovascular disease: diabetes $11.9 \%$, hypertension $25.4 \%$, dyslipidemia $40.2 \%$, hypertriglyceridaemia $28.3 \%$, overweight $\left(\mathrm{BMI} \geq 23 \mathrm{~kg} / \mathrm{m}^{2}\right) \quad 60.2 \%$ and metabolic syndrome $34.1 \%{ }^{8}$

Various other studies have also shown similar trends in the Indian population. ${ }^{9-15}$ An increasing prevalence of impaired glucose tolerance and diabetes in urban residents of Chennai was reported by Ramchandran et al. ${ }^{16}$ In 2002, Gupta et al showed that smoking and low physical activity levels were widespread in 20-39-year-old urban adults. ${ }^{17}$ Another important independent risk factor for CAD is a family history of CAD, as reported by Goel et al in 2003. ${ }^{18}$

Our study has clearly shown that among the middle class Indian population, there is a high prevalence of obesity, hypertension, dyslipidemia and diabetes, which are all modifiable CAD risk factors. The study has shown a direct correlation between increased BMI and dyslipidemia, diabetes and hypertension. CAD has a multifactorial aetiology, with many of the risk factors being influenced by lifestyle. Rapid change in dietary habits coupled with decreased physical activity in India as consequence of urbanisation may partly explain the increase in CAD. India is experiencing an epidemiological transition with high rates of urbanisation. ${ }^{19-22}$ This has led to economic improvement, the consequences of which are increased fast food consumption and tobacco usage, and decreased physical activity. With the introduction of an era of refined foods, sugar and hydrogenated oils, the traditional high complex carbohydrate, high fibre and low fat diet has been replaced by a diet rich in fats and simple sugars low in dietary fibre. ${ }^{23}$ One of the effects of this transition is a shift in the disease spectrum from communicable to non-communicable diseases, particularly $\mathrm{CAD}$ and diabetes. ${ }^{24-26}$ More importantly, $\mathrm{CAD}$ is affecting young Indians who comprise the productive workforce. The incidence of CAD in young Indians is 12$16 \%$, which is higher than in other ethnic groups worldwide. Lack of awareness of the preventable risk factors and ignorance of the disease are also important factors responsible for the increasing rate of CAD among Indians. ${ }^{27-32}$ In the present study, of the $21 \%$ of hypertensive study subjects, only $4.76 \%$ were aware they had condition and were on medication, while the remaining $16.22 \%$ were identified during the study. Similarly, of the $16 \%$ of the study population who had diabetes, $5.6 \%$ were diagnosed during the study. This shows that awareness and control of hypertension and diabetes was poor in the study population, indicating low detection and poor management of major CAD risk factors.

Prevention and control of the risk factors for CAD can reduce the rate of $\mathrm{CAD}$. This requires changes in the individual as well as at the community level. Modifying risk factors such as smoking, increased levels of body fat, consuming too much fat and salt, and a sedentary lifestyle together with the use of accessible and affordable preventive medicines, can lower the risk of CAD. Television and other media can be utilised to create awareness among the general population. Local resident welfare associations and religious groups can also be encouraged to promote a healthy lifestyle and exercise among the community.

\section{CONCLUSION}

The present study demonstrates a high prevalence of CAD risk factors in the Indian population, as the study population was representative of the national population, and reflects the rising trend in $\mathrm{CAD}$ in urban India. The incidence of CAD is likely to increase further because of rapid urbanisation and its accompanying lifestyle changes. Therefore, there is an immediate need to raise awareness among the general population about these risk factors, promote the correct diet and physical activity, and at the same time develop guidelines for screening and preventive therapeutic programmes to identify and manage individuals at high risk for future CAD.

Acknowledgements We are thankful to Dr RP Tripathi, Director of the Institute of Nuclear Medicine and Allied Sciences (INMAS) for his constant motivation and support. We further extend our thanks to the team in Bangalore consisting of Dr G Sripathy, Dr Jyotsana and Dr Bellubi who provided constant support for regional laboratories. We are also thankful to Col PJS Bhalla and Lt Col Ashustosh Kansal for laboratory work. Dr Naresh Gupta (Professor of Medicine, Maulana Azad Medical College, Delhi) and Dr Shantanu Sengupta (Institute of Genomics and Integrative Biology, Delhi) provided continuous guidance. Thanks are also due to each of our subjects for their consent and time.

Contributors TS: principal investigator; RSK: co-principal investigator of the study, medical evaluation and manuscript writing; RW, PC, MC and RA: medical evaluation of the study subjects and data compilation; YKS: statistical evaluation and analysis of the study population; JSe: dietary evaluation and data compilation; JSu, KB, SS, NR, TC, MS and SKS: laboratory sample analysis.

Funding The study was funded by a research grant from the Institute of Nuclear Medicine and Allied Sciences, Defence Research and Development Organisation, Ministry of Defence, New Delhi, India, under the Science and Technology Project (INM-310).

Competing interests None.

Ethics approval The Institutional Ethics Committee of the Institute of Nuclear Medicine and Allied Sciences approved this study.

Provenance and peer review Not commissioned; externally peer reviewed.

Data sharing statement No additional data are available. 
Open Access This is an Open Access article distributed in accordance with the Creative Commons Attribution Non Commercial (CC BY-NC 4.0) license, which permits others to distribute, remix, adapt, build upon this work noncommercially, and license their derivative works on different terms, provided the original work is properly cited and the use is non-commercial. See: http:// creativecommons.org/licenses/by-nc/4.0/

\section{REFERENCES}

1. Misra A, Nigam $P$, Hills AP, et al. Consensus physical activity guidelines for Asian Indians. Diabetes Technol Ther 2012;14:83-98.

2. Indrayan A. Forecasting vascular disease cases and associated mortality in India. Reports of the National Commission on Macroeconomics and Health, Ministry of Health and Family Welfare, India, 2005

3. Reddy KS, Yusuf S. Emerging epidemic of cardiovascular disease in developing countries. Circulation 1998;97:596-601.

4. Murray CJL, Lopez AD. Alternative projection of mortality and morbidity by cause 1990-2020:; Global Burden of Disease Study. Lancet 1997;349:1498-504.

5. Deepa R, Arvind K, Mohan V. Diabetes and risk factors for coronary artery disease. Curr Sci 2002;83:1497-505.

6. Gupta R, Sharma KK, Gupta A, et al. Persistent high prevalence of CV risk factors in the urban middle class in India: Jaipur Heart Watch-5. J Assoc Physicians India 2012;60:11-16.

7. Prabhakaran $\mathrm{D}$, Shah $\mathrm{P}$, Chaturvedi $\mathrm{V}$, et al. Cardiovascular risk factor prevalence among men in a large industry of northern India. Natl Med J India 2005;18:59-65.

8. Mohan V, Deepa R. Risk factors for coronary artery diseases in Indians. J Assoc Physicians India 2004;52:95-7.

9. Gupta R, Gupta VP, Ahluwalia NS. Educational status, coronary heart disease and coronary risk factors prevalence in a rural population of India. BMJ 1994;309:1332-6.

10. Singh RB, Ghosh S, Niaz MA, et al. Epidemiologic study of diet and coronary risk factors in relation to central obesity and insulin levels in the rural and urban populations of north India. Int J Cardiol 1995;47:245-55.

11. Ramachandran A, Snehalatha C, Latha E, et al. Clustering of cardiovascular risk factors in urban Asian Indians. Diabetes Care 1998;21:967-71.

12. Joseph A, Kutty VR, Soman CR. High risk for coronary heart disease in Thiruvananthapuram city: a study of serum lipids and other risk factors. Ind Heart J 2000;52:29-35.

13. Misra A, Pandey RM, Devi JR, et al. High prevalence of diabetes, obesity and dyslipidaemia in urban slum population in northern India. Int J Obes Relat Metab Disord 2001;25:1722-9.

14. Gupta R, Gupta VP, Sarna M, et al. Prevalence of coronary heart disease and risk factors in an urban Indian population: Jaipur Heart Watch-2. Indian Heart J 2002;54:59-66.

15. Mohan V, Deepa M, Farooq S, et al. Surveillance for the risk factors of cardiovascular disease among an industrial population in southern India. Natl Med J India 2008;21:8-13.
16. Ramchandran A, Snehlata C, Kapur A, et al. High prevalence of diabetes and impaired glucose tolerance in India: National Urban Diabetes Survey. Diabetologia 2001;44:1094-101.

17. Gupta R, Gupta VP, Bhagat N, et al. Obesity is the major determinant of coronary risk factors in India: Jaipur Heart Watch studies. Indian Heart J 2008;60:26-33.

18. Goel PK, Bharti BB, Pandey CM, et al. A tertiary care hospital-based study of conventional risk factors including lipid profile in proven coronary artery disease. Indian Heart J 2003;55:234-40.

19. Pais $\mathrm{P}$, Pogue J, Gerstein $\mathrm{H}$, et al. Risk factors for acute myocardial infarction in Indians: A case-control study. Lancet 1996;348:358-63.

20. Gopalan S, Shiva M. National profile on women, health and development: India. New Delhi: Voluntary Health Association of India, 1999.

21. Ramanakumar AV. Reviewing disease burden among rural Indian women. Online J Health Allied Sci 2004;2:1.

22. Yusuf S, Hawken S, Ounpuu S, et al. Effect of potentially modifiable risk factors associated with myocardial infarction in 52 countries (the INTERHEART study): Case-control study. Lancet 2004;364:937.

23. Drewnowski A, Popkin BM. The nutrition transition: new trends in the global diet. Nutr Rev 1997;55:31-43.

24. Sharma M, Ganguly KN. Premature coronary artery disease in Indians and its associated risk factors. Vasc Health Risk Manag 2005;1:217-25.

25. Mokdad AH, Ford ES, Bowman BA, et al. Prevalence of obesity, diabetes, and obesity-related health risk factors. JAMA 2003;289:76-9.

26. Mohan V, Deepa R, Rani SS, et al. Prevalence of coronary artery disease and its relationship to lipids in a selected population in South India: The Chennai Urban Population Study (CUPS No. 5) J Am Coll Cardiol 2001;38:682-7.

27. Deepa $R$, Shanthirani CS, Pradeepa R, et al. Is the 'rule of halves' in hypertension still valid? Evidence from the Chennai Urban Population Study. J Assoc Physicians India 2003;1:153-7.

28. Zachariah MG, Thankappan KR, Alex SC, et al. Prevalence, correlates, awareness, treatment, and control of hypertension in a middle-aged urban population in Kerala. Indian Heart $J$ 2003:55:245-51.

29. Gupta AK, Ahluwalia SK, Negi PC, et al. Awareness of hypertension among a north Indian population. J Indian Med Assoc 1998;96:298-9.

30. Chadha SL, Radhakrishnan S, Ramachandran K, et al. Prevalence, awareness and treatment status of hypertension in urban population of Delhi. Indian J Med Res 1990;92:233-40.

31. Qiao Q, Hu G, Tuomilehto J, et al. Age- and sex-specific prevalence of diabetes and impaired glucose regulation in 11 Asian cohorts. Diabetes Care 2003;26:1770-80.

32. Mohan V, Shanthirani CS, Deepa R. Glucose intolerance (diabetes and IGT) in a selected South Indian population with special reference to family history, obesity and lifestyle factors-The Chennai Urban Population Study (CUPS14). J Assoc Physicians India 2003;51:771-7. 